15. Maeng DD, Martsolf GR, Scanlon DP, Christianson JB. Care coordination for the chronically ill: understanding the patient's perspective. Health Serv Res. 2012;47(5):1960-1979.

16. Craig C, Eby D, Whittington J. Care coordination model: better care at lower cost for people with multiple health and social needs. IHI Innovation Series white paper. Institute for Healthcare Improvement; 2011.

17. Coleman EA, Eilertsen TB, Magid DJ, Conner DA, Beck A, Kramer AM. The association between care co-ordination and emergency department use in older managed care enrollees. Int J Integr Care. 2002;2:e03.

18. Coleman EA, Parry C, Chalmers S, Min SJ. The care transitions intervention: results of a randomized controlled trial. Arch Intern Med. 2006;166(17):1822-1828.

19. Peikes D, Chen A, Schore J, Brown R. Effects of care coordination on hospitalization, quality of care, and health care expenditures among Medicare beneficiaries: 15 randomized trials. JAMA. 2009; 301(6):603-618.

20. Kane B, Sands DZ. Guidelines for the clinical use of electronic mail with patients. The AMIA Internet Working Group, Task Force on Guidelines for the Use of Clinic-Patient Electronic Mail. J Am Med Inform Assoc. 1998;5(1):104-111.

21. Chen AH, Yee HF Jr. Improving the primary care-specialty care interface: getting from here to there. Arch Intern Med. 2009;169 (11):1024-1026.

22. Zulman DM, Asch SM, Martins SB, Kerr EA, Hoffman BB, Goldstein MK. Quality of care for patients with multiple chronic conditions: the role of comorbidity interrelatedness. J Gen Intern Med. 2014;29(3):529-537.

23. Parchman ML, Pugh JA, Romero RL, Bowers KW. Competing demands or clinical inertia: the case of elevated glycosylated hemoglobin. Ann Fam Med. 2007;5(3):196-201.

24. Boyd CM, Darer J, Boult C, Fried LP, Boult L, Wu AW. Clinical practice guidelines and quality of care for older patients with multiple comorbid diseases: implications for pay for performance. JAMA. 2005;294(6):716-724.
25. Fortin M, Bravo G, Hudon C, et al. Relationship between multimorbidity and health-related quality of life of patients in primary care. Qual Life Res. 2006;15(1):83-91.

26. Egede LE. Major depression in individuals with chronic medical disorders: prevalence, correlates and association with health resource utilization, lost productivity and functional disability. Gen Hosp Psychiatry. 2007;29(5):409-416.

27. Maciejewski ML, Bayliss EA. Approaches to comparative effectiveness research in multimorbid populations. Med Care. 2014;52 (Suppl 3):S23-S30.

28. PCORI (Patient-Centered Outcomes Research Institute) Methodology Committee. The PCORI methodology report. http://www.pcori. org/assets/2013/11/PCORI-Methodology-Report.pdf. Published Nov 2013.

29. Fortin M, Stewart M, Poitras ME, Almirall J, Maddocks H. A systematic review of prevalence studies on multimorbidity: toward a more uniform methodology. Ann Fam Med. 2012;10(2):142-151.

30. DuGoff EH, Dy S, Giovannetti ER, Leff B, Boyd CM. Setting standards at the forefront of delivery system reform: aligning care coordination quality measures for multiple chronic conditions. J Healthc Qual. 2013;35(5):58-69.

31. National Quality Forum. Multiple chronic conditions measurement framework. Washington, DC: National Quality Forum; 2012.

32. Boyd C, Fortin M. Future of multimorbidity research: How should understanding of multimorbidity inform health system design? Public Health Rev. 2010;32(2):451-474.

33. Jaén CR, Crabtree BF, Palmer RF, et al. Methods for evaluating practice change toward a patient-centered medical home. Ann Fam Med. 2010;8(Suppl 1):S9-S20, S92.

34. Scholle SH, Asche SE, Morton S, Solberg LI, Tirodkar MA, Jaén CR Support and strategies for change among small patient-centered medical home practices. Ann Fam Med. 2013;11(Suppl 1):S6-S13.

35. Tomoaia-Cotisel A, Scammon DL, Waitzman NJ, et al. Context matters: the experience of 14 research teams in systematically reporting contextual factors important for practice change. Ann Fam Med. 2013;11(Suppl 1):S115-S123.

\title{
EDITORIAL
}

\section{Publishing Patient-Centered Outcomes Research}

Ann Fam Med 2014;12:503-504. doi: 10.1370/afm.1723.

$\mathrm{T}$ The still new Patient-Centered Outcomes Research Institute (PCORI) is changing the world of clinical research by bringing the voice of patients and other stakeholders into the design, conduct, and interpretation of research. PCORI is both championing and riding the wave of movements that combine rigor and relevance, carefulness and openness, expertise and inclusive participation. These movements challenge entrenched oligarchies. Now PCORI is seeking to add to the process of timely, accessible, transparent communication of research results to increase the credibility of patient-centered outcomes research.

Having just completed a public comment period, PCORI will soon declare a process for peer review and public release of its sponsored research findings. The exact details still are being determined, but we know that the process must comply with the legal statutes that created PCORI as an independent, but federally funded organization. We also know that PCORI will be working to find the sweet spot between the needs and desires of researchers, scientific and lay publishers, and the diverse end users of patient-centered outcomes research.

The statutes call for:

- A process for peer review of primary research to assess scientific integrity and adherence to methodological standards

- Making research findings available to clinicians, patients, and the general public: 
- "Not later than 90 days after the conduct or receipt of research findings"

- Ensuring that the findings are conveyed:

- "In a manner that is comprehensible and useful to patients and providers in making health care decisions"

- Discusses "considerations specific to certain subpopulations, risk factors, and comorbidities, as appropriate"

- Includes limitations of the research

- Making "available to the public and disclos[ing] through the official public Internet website of the Institute":

- Information contained in research findings

- The process and methods for the conduct of research, including the identity of the entity and the investigators and any conflicts of interests The final process seems likely to involve:

- Registration of PCORI studies with the appropriate registry or public database

- Submission of a final report that PCORI will peer review according to its methodological standards. The report will include a 500-word abstract for medical professionals, a standalone results table, an ancillary information section that lists the identity of investigators, and any conflicts of interest / links to industry

- Posting of the peer-reviewed report and a lay audience summary

- Working to coordinate with traditional academic publication outlets and other dissemination vehicles and processes

There will be challenges with the PCORI process and its implementation, as the medical research and publication worlds lurch toward more timely and inclusive processes that balance the benefits of scientific peer review with the need for rapid accessibility and interactive interpretation of credible findings. The challenges include: synchronizing the time frames of research, review, and scientific and lay publication processes that may not always match PCORI statutory requirements, and managing the dissemination of continuing discoveries after the PCORI final reports have been processed. To the extent that PCORI and its funded research is successful in fostering a truly participatory research community of relevant stakeholders, however, the needs and desires of researchers, scientific and lay publishers, and research end users will begin to come together.

Whatever the final form of the PCORI process, Annals of Family Medicine is committed to the principles of patient-centered outcomes research, the involvement of relevant stakeholders in all phases of the process from the generation of the question to the conduct of the research, and the participatory, evolving implementation and dissemination of the findings. We look forward to working with authors, diverse stakeholders, and with PCORI on being part of a larger process to make patient-centered outcomes research easily, credibly, and interactively accessible.

A number of features of Annals are already designed to make research accessible, credible, and interactive. Annals makes the full text of articles, brief lay-language article summaries, and interactive online discussion available free of charge to anyone with Internet access. Annals peer reviews and accepts articles without publication fees, and publishes without commercial sponsorship. Upon acceptance, we work with authors to identify diverse stakeholders potentially affected by the research and ask the stakeholders to join an online discussion that is part of the permanent record of the journal. We also work directly with the lay, professional, and social media to assure that the content of articles published in Annals is shared in diverse venues that reach audiences who don't regularly read scientific journals.

Annals publishes not only original research articles, but also high-impact research briefs, systematic reviews, methodology, theory, essays, and special articles that provide timely outlets to convey different ways of knowing. We will continue to develop our publication processes to meet to the evolving needs of the diverse communities who care about patientcentered outcomes research, and to help foster the participatory implementation and dissemination of that research to people and communities who will benefit from its use.

To read or post commentaries in response to this article, see it online at http://www.annfammed.org/content/12/6/503.

Key words: patient outcome assessment; quality of health care; primary health care; patient-centered care, PCORI

Submitted September 20, 2014; submitted, revised, September 26, 2014; accepted October 1, 2014. 